ANADOLU, J. of AARI

ISSN: $1300-0225$ (Print)

E-ISSN: 2667-6087 (Online)

2020, 30 (2): 153-162

DOI: $10.18615 /$ anadolu. 834830

\title{
Kısıntılı Sulama Koşullarında Dallı Darı (Panicum virgatum L.) Çeşitlerinin Tane Verimi ve Bazı Özelliklerinin Belirlenmesi
}

\author{
Erdal GÖNÜLAL ${ }^{1^{*}}$ (D) Süleyman SOYLU ${ }^{2}$ \\ ${ }^{1}$ Bahri Dağdaş Uluslararası Tarımsal Araştırma Enstitüsü, Konya/TURKEY \\ ${ }^{2}$ Selcuk Üniversitesi, Ziraat Fakültesi Tarla Bitkileri Bölümü, Konya/TURKEY \\ ${ }^{1}$ https://orcid.org/0000-0002-1621-0892 \\ ${ }^{2}$ https://orcid.org/0000-0002-0420-5033 \\ * Corresponding author (Sorumlu yazar): erdalgonulal@hotmail.com \\ Received (Geliş tarihi): 12.06.2020Ａccepted (Kabul tarihi): 29.07.2020
}

\begin{abstract}
ÖZ: Konya Karapınar koşullarında tesadüf bloklarında bölünmüş parseller deneme desenine göre, üç tekerrürlü olarak üç yll (2016-2018 yll) süreyle yürütülen bu çalı̧̧mada; ana parsel olarak üç sulama konusu ( $S_{I}$ : Tam sulama, eksik nemin tarla kapasitesine getirilmesi; $S_{2}$ : $S_{1}$ 'in \% 75' i kadar sulama; $S_{3}$ : $S_{1}$ 'in \% 50' si kadar sulama) ve altı dall darl çeşidi (Alamo, Kanlow, Shelter, Shawnee, Cave in rock ve Trailblazer) materyal olarak kullanılmıştır. Çalışmada su kısıtı bakımından ortalama birim alan tane verimi $15,4 \mathrm{~kg} / \mathrm{da}\left(S_{3}\right)-51,6 \mathrm{~kg} / \mathrm{da}\left(S_{1}\right)$ arasında, bin tane ağırlı̆̆ $1,22 \mathrm{~g}\left(S_{3}\right)-1,41 \mathrm{~g}\left(S_{1}\right)$ aralığında ve hasat indeksi 1,17 $\left(S_{3}\right)$ - 2,52 ( $\left(S_{1}\right)$ aralığında belirlenmiştir. Araştırmada çeşitler açısından ortalama birim alan tane verimi 5,7 $\mathrm{kg} / \mathrm{da}$ (Alamo)-52,7 kg/da (Cave in rock) aralığında, bin tane ă̆ırlı̆̆ $0,82 \mathrm{~g}$ (Alamo)-1,66 $\mathrm{g}$ (Cave in rock) aralığında ve hasat indeksi \%0,21 (Alamo)- \%3,57 (Cave in rock) aralı̆̆ında belirlenmiştir. Çalışma ile ova (lowland) ekotipindeki çeşitlerin düşük birim alan tane verimi, bin tane ağırlığl ve hasat indeksi değerine sahip olduğu; yayla (upland) ekotipindeki çeşitlerin ise, birim alan tane verimi ve tane iriliğinin daha fazla olduğu ve sulamanın incelenen parametreler üzerinde etkili olduğu saptanmıștır.
\end{abstract}

Anahtar Kelimeler: Dallı darı, Panicum virgatum L., bin tane ağırlı̆̆ı, hasat indeksi, su kısıtlaması, birim alan tane verimi.

\section{Determining of Seed Yield and some Yield Characteristics of Switchgrass (Panicum virgatum L.) Varieties under Water Deficits Conditions}

\begin{abstract}
Experiments were conducted for three years (2016, 2017 and 2018) under ecological conditions of Konya-Karapinar region of Turkey in randomized blocks in split plots experimental design with 3 replications. Three irrigation treatments $\left(S_{1}:\right.$ Full-irrigation with no water deficit, $S_{2}: 75 \%$ of $S_{1}$ irrigation, $S_{3}: 50 \%$ of $S_{1}$ irrigation) were placed into main plots and six switchgrass cultivars (Alamo, Kanlow, Shelter, Shawnee, Cave in rock ve Trailblazer) were placed into the subplots. According to result of were obtained in terms of cultivars average seed yield were varied between $5.7 \mathrm{~kg} \mathrm{da}^{-1}$ (Alamo) $52.7 \mathrm{~kg} \mathrm{da}{ }^{-1}$ (Cave in rock), thousand-kernel weights between $0.82 \mathrm{~g}$ (Alamo) $-1.66 \mathrm{~g}$ (Cave in rock) and harvest index between $0.21 \%$ (Alamo) - 3.57\% (Cave in rock). In this study, it was determined that the varieties in lowland ecotype had low average seed yield, thousand-kernel weight and harvest index values, but the upland varieties had higher average seed yield and seed size and irrigation or water disability was effective factor on the parameters studied.
\end{abstract}

Keywords: Switchgrass, Panicum virgatum L., thousand-kernel weight, harvest index, water disability, average seed yield.

\section{GíRiș}

Dallı darı çok yıllık (10-15 yıl), suyu etkin kullanan, marjinal alan ve kurak koşullarda biyokütle üretebilen, her yıl toprak işleme gerektirmeyerek, toprak organik karbonunu artıran (David ve Ragauskas, 2010) ve erozyonu önleyen çevre dostu bir sıcak iklim tahıl bitkisidir. Düşük maliyetli silaj ve kuru ot olarak değerlendirilmesinin yanında, 
yapay mera 1slahında da kullanılmakta ayrica yüksek oranda biyoetanol üretme kapasitesine de sahiptir (Soylu ve ark., 2010).

Morfolojik karakterleri ve yetişme çevrelerine göre upland (yayla tipi) ve lowland (ova tipi) olmak üzere iki farklı ekotipi bulunmaktadır. Lowland ekotipindeki çeşitler genellikle daha boylu, sap kalınlığ1 ve ağırlığ fazla ve genel de enerji üretim amaçlı kullanılırken; upland tipler ise daha kısa boylu, çok kardeşlenen, ince-narin saplı ve genelde hayvan beslemesinde kullanılmaktadır (Hultquist ve ark., 1996 ).

Dallı darının çok sayıda tane vermesi, tanesinin ekimiyle üretilmesi, çok yıllık olması, soğuğa ve kurağa toleranslı olması ve geniş coğrafi marjinal alanlara adaptasyon yeteneğinden dolayı, Türkiye açısından alternatif bir bitki türü örneği teşkil etmektedir. Su kaynakları yeterli olmayan alanlarda üreteceği biyokütle ile hayvancılık açısından sürdürülebilir bir üretime olanak sağlaması ve sulu tarım alanları üzerindeki baskının azaltılması açısından önemli bir bitki olan dallı darı Kuzey Amerika kökenli olmasına rağmen, 2000'li y1llardan sonra Avrupa ülkeleri ve Türkiye'de yürütülen çalışmalarda olumlu sonuçlar vermiştir (Soylu ve ark., 2010).

Upland ve lowland olmak üzere iki ekotipi olan temel kromozom sayıs $\mathrm{x}=9$ olan dallı darıda ploidi seviyesi diploid $(2 \mathrm{n}=2 \mathrm{x}=18)$ ile duodecoploid $(2 n=12 x=108)$ arasında değişmektedir. Yabancı döllenen dallı darıda lowland (ova) çeşitler tetraploid, upland çeşitler ise tetraploid ya da octaploid nadiren ise hexaploiddirler (Narasimhamoorthy ve ark., 2008; Casler, 2012).

Dallı darı ıslahı yetiştiriciliğinde ana odak, biyokütle veriminin artması olmasına rağmen, dallı darının ticari ve geniş olarak yayılımı için gerekli olan tane verim talebini karşılamak için bitki başına tane veriminin ve verim bileşenlerinin geliştirilmesi de çok önemlidir. Vogel (2000), yeni çeşitlerin tohum üretiminin beklenen talebi karşılamak için yeterli olmasını sağlamak amacıyla biyokütle ve hayvan yemi üretimi için geliştirilen yeni çeşitlerin seçimi ve değerlendirilmesi sırasında tane verimine dikkat edilmesi gerektiğini belirtmiştir. Dallı darı bitkisinin yeni alanlarda yaygınlaşması için en önemli konulardan biri de, gerekli tohumluğun bu alanlarda ekonomik olarak üretilebilmesidir.

İklim değişikliğinin olumsuz etkilerine karş1 marjinal alanlarda dallı darı bitkisi kendine has önemli özellikleri ile alternatif bir bitki olarak görülmektedir. Türkiye'nin birçok alanında yürütülen adaptasyon çalışmalarında olumlu sonuçlar veren bu bitkinin çoğaltılması ve geniş sahalara plantasyonu, taneyle çoğaltılabilmesi ile olanaklidır. Tane verimini agronomik uygulamalar etkilemekte olup, bu çalışma ile Orta Anadolu koşullarında su kısıtı şartlarında; altı dallı darı çeşidinin üç yıllık birim alan tane verimi, bin tane ağırlığ 1 ve birim alan hasat indeksi araştırılmıştır.

\section{MATERYAL ve METOT}

Çalışma üç yıl süreyle (2016, 2017 ve 2018), Konya-Karapınar $\left(37^{0} 41^{\prime} 09.88^{\prime \prime} \mathrm{K}\right.$ ve $33^{\circ} 30^{\prime}$ 13.00" D coğrafi koordinatta) ekolojik koşullarında üç tekrarlamalı olarak yürütülmüştür. Deneme alanı kara iklimine sahip olup; yaz yağışları düşük, toplam yıllık yağış miktarı 300 mm'nin altında ve yağış dağılım rejimi düzensiz ve yağışların önemli kısmı kışın gerçekleşen bir agroekolojik zondur.

Çalışmanın yürütüldüğü koşullarda yağış miktarı uzun yıllar ortalamas1 olarak 291,2 mm olup, çalışmanın yürütüldüğ $\ddot{u} \quad 2016,2017$ ve 2018 yıllarında sirasıyla; $286,2 \mathrm{~mm}, 249,6 \mathrm{~mm}$ ve 275,4 mm olarak gerçekleşmiştir. Dallı darının sulandığı ve gelişme gösterdiği Nisan- Eylül arası yağışlara bakıldığında uzun yıllar için $93,5 \mathrm{~mm}$ yağış gerçekleştiği görülmektedir. Araştırma sürecinde ise yağış miktarı; 2016 yılında 98,6 mm, 2017 yılında $117,8 \mathrm{~mm}$ ve 2018 y1linda ise $103,3 \mathrm{~mm}$ olarak gerçekleşmiştir. Çalışmanın üç yılında da yetişme dönemindeki yağış miktarları uzun yıllar yağış ortalamasindan daha fazla $(93,5 \mathrm{~mm})$ olmuştur (Çizelge 1). 
Çizelge 1. Araştırma alanının bazı iklim özellikleri (Anonim, 2018).

Table 1. Some climatic properties of the experimental area (Anonim, 2018).

\begin{tabular}{|c|c|c|c|c|}
\hline \multirow{2}{*}{$\begin{array}{l}\text { İklim özellikleri } \\
\text { Climatic properties }\end{array}$} & \multicolumn{4}{|c|}{ Yillar (Years) } \\
\hline & 2016 & 2017 & 2018 & $\begin{array}{c}\text { Long terms } \\
(1963-2018)\end{array}$ \\
\hline Ort.Sic. $\left({ }^{\circ} \mathrm{C}\right)$ (Average temp.) & 12,3 & 11,7 & 12,3 & 12,0 \\
\hline Ort. minimum sicaklık $\left({ }^{\circ} \mathrm{C}\right)$ (Average min. temp.) & 1,1 & $-0,7$ & $-0,5$ & $-3,9$ \\
\hline Ort. maksimum sicaklik $\left({ }^{\circ} \mathrm{C}\right)$ (Average max. temp.) & 26,9 & 24,7 & 26,9 & 26,1 \\
\hline Nisan-Eylül yağış (mm) (Apr.-Sept. precipitation) & 98,6 & 117,8 & 103,3 & 93,5 \\
\hline Toplam yağıș (mm) (Total precipitation) & 286,2 & 249,6 & 275,4 & 291,2 \\
\hline
\end{tabular}

Toprak özelliklerine bakıldığında deneme alanının özellikle 0-30 cm'lik katmanının kumsal yapıda olduğu, organik maddece fakir, kireç miktarı ve pH'1 yüksek ve tuz sorunu olmayan bir alan olduğu belirlenmiştir (Çizelge 2). Çalışmada Amerika Birleşik Devletleri Tohum Gen Bankası ve yurtdışı özel kuruluşlardan daha önce temin edilen ikisi lowland ekotipinde (Alamo ve Kanlow) ve dördü upland ekotipinde (Shawnee, Shelter, Trailblazer ve Cave in rock) olmak üzere toplam altı dallı darı çeşidi materyal olarak kullanılmıştır.

Çalışmaya 2015 yılında dallı darının plantasyonu ile başlamıştır. Deneme alanına 2015 yılı Haziran ayında toprak hazırlığı yapıldıktan sonra, her parsel için toprak işleme anında $10 \mathrm{~kg} / \mathrm{da} \mathrm{P}_{2} \mathrm{O}_{5}$ ve 3 $\mathrm{kg} / \mathrm{da} \mathrm{N}$ hesabıyla taban gübre verilmiştir. Sira aras $15 \mathrm{~cm}$ olacak şekilde çizel ile açılan sıralara ekim; 1 Temmuz 2015 tarihinde, $1 \mathrm{~cm}$ derinliğe $400 \mathrm{bitki} / \mathrm{m}^{2}$ olacak şekilde elle yapılarak, toprak sıkıştırılmıştır (Soylu ve ark., 2010). Parsel büyüklüğ̈̈; $5 \mathrm{~m}$ uzunluk ve 1,8 $\mathrm{m}$ genişlik (6 sıra) olmak üzere $9 \mathrm{~m}^{2}$ 'lik alanlardan oluşmuştur. Biyokütle ve birim alanda tane hasadı, parsel başı ve sonundan 1 metre, kenarlardan ise 1 sira parsel dışı olarak atılmıș kalan, 3,6 $\mathrm{m}^{2}$ den ölçüm ve gözlemler yapılmış, veriler dekara çevrilmiștir. Tesadüf bloklarında bölünmüş parseller deneme desenine göre yürütülen çalışmada; ana konu olarak üç sulama konusu $\left(\mathbf{S}_{\mathbf{1}}\right.$ : Tam sulama, eksik nemin tarla kapasitesine getirilmesi; $\mathbf{S}_{2}: \mathrm{S}_{1}{ }^{\prime}$ in $\%$ 75 ' i kadar sulama; $\mathbf{S}_{3}: \mathrm{S}_{1}{ }^{\prime}$ in $\%$ 50' si kadar sulama) alt konu olarak ise altı çeşit (Alamo, Kanlow, Shelter, Shawnee, Cave in rock ve Trailblazer) ile çalışılmıștır.

Tesis y1lı olan 2015' te ekimle birlikte biçime kadar olan su ihtiyacını karşılamak üzere tüm konulara Temmuz - Eylül ayları arasında toplam $150 \mathrm{~mm}$ su verilmiştir. Tesis yılında 1 Kasım 2015 tarihinde yerden $15 \mathrm{~cm}$ yükseklikten ot biçimi yapılarak parsellerdeki bitkilerin kışa girmesi sağlanmıştır. Su kısıtı konularının uygulanmaya başladığı ve verilerin alınmaya başladığı 2016 yılı Nisan ayından itibaren üç yıl boyunca yetişme döneminde topraktaki nem gravimetrik yönteme göre izlenmiş ve $0-90 \mathrm{~cm}$ toprak derinliğindeki topraktaki faydalı suyun \% 50-55'i kullanıldığında $\mathrm{S}_{1}$ konusu tarla kapasitesine getirilecek şekilde damla sulama yapılmıștır. Sulama sisteminde 75' lik borular ve bundan çıkıș yapılan $40 \mathrm{~cm}$ damlatıcı aralığ 1 ve 2,0 1/h debisi olan $166 \mathrm{~mm}$ 'lik basınç ayarlı damla sulama boruları kullanılmıştır. Her parsele 4 sıra lateralin döşendiği çalışmada parsellere verilen suyu belirlemek için su sayacı kullanılmıştır. Tam sulama $\left(\mathrm{S}_{1}\right)$ konusuna verilecek sulama suyu miktarı deneme alanının hacim ağırlığı, tarla kapasitesi, solma noktası belirlendikten aşağıdaki eşitlik yardımı ile hesaplanmıştır (Kara, 2011).

$$
\mathrm{dn}=(\mathrm{TK}-\mathrm{MN}) \times \mathrm{D} \times 100^{-1}
$$

Eşitlikte;

$\mathrm{dn}=$ Her sulamada uygulanacak net sulama suyu miktar1 (mm),

TK = Tarla kapasitesi (hacim \%' si olarak),

$\mathrm{MN}=$ Faydalı su kapasitesinin \%50-55, i tüketildiğinde dallı darı etkili kök derinliğindeki mevcut nem (hacim \%' si olarak),

$\mathrm{D}=$ Etkili kök derinliği (mm)

Su kısıtı konularında ise $S_{1}$ konusuna göre kısıntı hesap edilmiştir. 2016 yılında damla sulama ile 12 sulama, 2017 ve 2018 yllinda ise 11 sulama yapılmıștır. Tam sulama konusuna $\left(\mathrm{S}_{1}\right) 2016$ yılında $480 \mathrm{~mm}, 2017$ yılinda $436 \mathrm{~mm}$ ve 2018 yılında ise $450 \mathrm{~mm}$ sulama suyu verilmiştir. $\mathrm{S}_{2}$ (2016 y1l1 : $360 \mathrm{~mm}, 2017$ y1l1: $327 \mathrm{~mm}, 2018$ y1l $338 \mathrm{~mm}$ ) ve $\mathrm{S}_{3}$ ( 2016 y1lı: $240 \mathrm{~mm}, 2017$ y1lı: 218 $\mathrm{mm}, 2018$ yılı: $225 \mathrm{~mm}$ ) konularına ise oranlarına göre kısıtlamaya gidilerek sulama yapılmıştır. Çalışmada her üç yılda da Mayıs ayında dekara 15 kg saf azot verilmiştir (Soylu ve ark., 2010). 
Çizelge 2. Araştırma alanının bazı toprak özellikleri (Anonim, 2017).

Table 2. Some soil properties of the experimental area (Anonim, 2017).

\begin{tabular}{|c|c|c|c|c|c|c|c|c|c|c|c|c|c|}
\hline 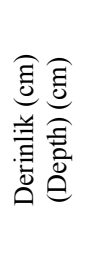 & 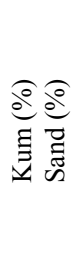 & 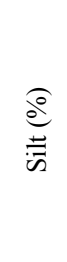 & 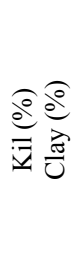 & 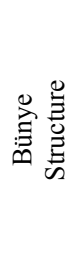 & $\frac{\partial}{\frac{d}{b}}$ & $\underbrace{\frac{2}{b}}_{\bar{c}}$ & 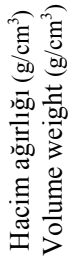 & I & 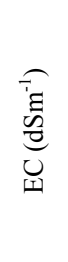 & 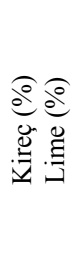 & 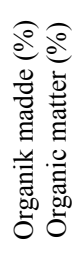 & 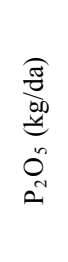 & \begin{tabular}{l}
$\frac{\pi}{0}$ \\
$\frac{\pi}{20}$ \\
0 \\
0 \\
\cline { 1 - 1 }
\end{tabular} \\
\hline $0-30$ & 58,1 & 22,8 & 19,1 & SCL & 20 & 9,6 & 1,37 & 7,8 & 0,42 & 33,5 & 1,3 & 14,5 & 33 \\
\hline $30-60$ & 301 & 20,3 & 49,6 & $\mathrm{C}$ & 24,5 & 12,6 & 1,3 & 8,1 & 0,45 & 28,7 & 1,1 & 5,7 & 26 \\
\hline $60-90$ & 160 & 24,4 & 59,6 & $\mathrm{C}$ & 28 & 15,4 & 1,22 & 8,2 & 0,44 & 29,4 & 0,6 & 2,6 & 24 \\
\hline
\end{tabular}

Çalışmada ilk yıl bitkiler 17 Nisan, 2017 yılında 21 Nisan ve 2018 y1lında ise 15 Nisan tarihinde uyanmaya başlamış ve üç yıl içinde çeşitlerin çiçeklenme tarihleri belirlenmiştir (Çizelge 3). Parsellerde biyokütle ve tane hasadi 2016 yılında 1 Kasım, 2017 yılında 30 Ekim, 2018 yılında ise 3 Kasım tarihinde, her parselde kenar tesirleri atıldıktan sonra elle yapılmıştır. Her parselde salkımlar kesilip harmanlanmış ve temizlenmiştir.

Hasat indeksi her parselden elde edilen tane veriminin biyolojik verime bölünmesi ile belirlenmiştir. (Turan, 2008). Bin tane ağırlığı 4 adet 100 tanenin sayılıp tartılarak ortalamasının alınmasıyla (Soylu ve ark., 2010) hesaplanmış, hasat indeksi ise Sarı ve Ünay (2015)'ın uyguladığı yönteme göre hesap edilmiştir. Sonuçlarının değerlendirilmesinde ve ortalamaların karşılaştırmasında istatistiksel analiz ve LSD testi uygulanmıştır (Steel ve Torrie, 1980). Çalışmadan elde edilen veriler JMP 11.2.1 (Anonymous, 2007) paket istatistik programı kullanılmıştır. Konular arasındaki farklıklar ve gruplandırmalar LSD testine göre belirlenmiştir (Steel ve Torrie, 1980).

\section{BULGULAR ve TARTIŞMA}

Tam sulama ve su kısıtlılı̆g koşullarında dallı darının tane verimi, bin tane ağırlığ 1 ve hasat indeksi özelliklerinin incelendiği çalışmaya ait varyans analiz tablosu Çizelge 4'te verilmiştir. Homojenliği kontrol edilip y1l birleştirmesi yapılan çalışmada; su ve çeşit konuları arasındaki farklar, incelenen bütün parametreler için istatistiki olarak önemli bulunmuştur.

\section{Birim alan tane verimi}

Konya- Karapınar koşullarında üç yıl süreyle yürütülen çalışmada tane verimine ait sonuçlar Çizelge 5'te verilmiş olup, denemenin ilk yılı olan 2016 yılına $(21,5 \mathrm{~kg} / \mathrm{da})$ göre 2017 y1lı $(38,9$ $\mathrm{kg} / \mathrm{da})$ ve 2018 y1lında $(39,9 \mathrm{~kg} / \mathrm{da})$ tane veriminde artış olmuştur. Çalışmada su kısıtlllığ tane verimini olumsuz etkilemiştir. Tam su konusunda tane verimi $51,6 \mathrm{~kg} / \mathrm{da}$ olurken, \% 50 su kisitı uygulanan $\mathrm{S}_{3}$ konusunda en düşük tane verimi 15,4 $\mathrm{kg} / \mathrm{da}$ olarak belirlenmiştir (Çizelge 5).

Çok yıllık bir bitki olan dallı darıda yıl ilerledikçe verim ve verim ögeleri artmakta (Sharma ve ark., 2003; Soylu ve ark., 2010), buna paralel olarak birim alandaki tane verimi de artmaktadır. Su kısıtlılığı dallı darıda biyokütle verimini olumsuz etkilediği gibi, özellikle çiçeklenmenin de gecikmesine neden olmuştur (Çizelge 3) ve generatif dönemin geç başlaması ve kısalmasını da etkilemiş̧ir. Çiçeklenmeden sonra tane oluşması için yeterli zamanın kalmaması; çiçeklenme oranının azalmasına ve ayrıca çiçeklenme dönemindeki su stresi, döllenme ve tane veriminin olumsuz etkilemesine neden olmuştur.

Çeşitler bazında lowland ekotipindeki Alamo (5,7 $\mathrm{kg} / \mathrm{da})$ ve Kanlow $(9,3 \mathrm{~kg} / \mathrm{da})$ çeşitlerinin en düşük tane verimine sahip olduğu (Soylu ve ark., 2011) bu durumun Çizelge 3'te görüldüğü üzere bu çeşitlerin çiçeklenme zamanlarının upland çeşitlere göre çok daha geç olduğu, özellikle bu çeşitlerde su kısıtlılığ1 durumunda çiçeklenmenin daha geç olmasıyla, verimlerin daha da düşük olduğu görülmektedir (Çizelge 3 ve 5). Lowland ekotipindeki Kanlow ve Alamo çeşitlerinin tane 
veriminin düşük olmasında bin tane ağırlıklarının da düşük olması etkili olmuştur (Çizelge 6).

Şekil 1'de görüldüğü üzere yapılan regresyon analizinde bütün dallı darı çeşitlerinde sulama suyu miktarı ve tane verimi arasında doğrusal pozitif bir ilişki belirlenmiş olup artan sulama suyu miktarı ile birlikte birim alan tane verimi de artmıştır. Çeşit ortalamaları üzerinden çalışmada en yüksek tane verimi Cave in rock $(52,7 \mathrm{~kg} / \mathrm{da})$ ile Shelter $(50,1 \mathrm{~kg} / \mathrm{da})$ çeşitlerinden elde edilmiştir. Su x çeşit etkileşimi açısından en yüksek ve düşük tane verimi $S_{1}$ uygulamasinda Shelter $(75 \mathrm{~kg} / \mathrm{da})$ ile Alamo $(11,9 \mathrm{~kg} / \mathrm{da})$ çeşitlerinden, $\mathrm{S}_{2}$ konusunda Cave in rock $(54,3 \mathrm{~kg} / \mathrm{da})$ ile Alamo $(4,1 \mathrm{~kg} / \mathrm{da})$ çeşitlerinden, $\mathrm{S}_{3}$ sulamasında ise Cave rock $(32,6$
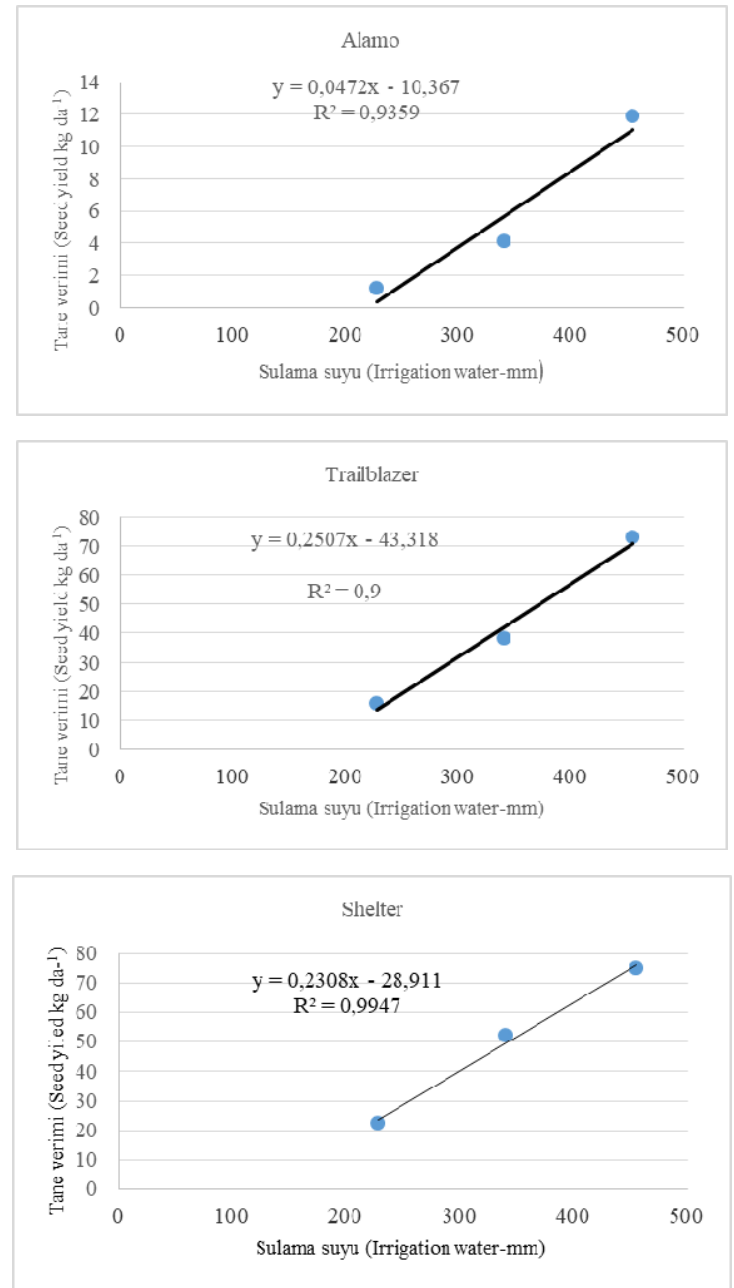

$\mathrm{kg} / \mathrm{da})$ ile Alamo $(1,2 \mathrm{~kg} / \mathrm{da})$ çeşitlerinden elde edilmiştir (Şekil 2).

Dallı darı ile ilgili çalışmalarda biyokütle ve diğer parametrelerle ilgili birçok çalışma yapılmasına rağmen, birim alan tane verimi ile ilgili daha az çalışmaya rastlanılmıştır. Farklı ekoloji ve çeşitlerde yürütülen bu çalışmalarda tane verimini Boe (2007), 15,6-46,0 kg/da, Das ve ark. (2009), 22,3$74,2 \mathrm{~kg} / \mathrm{da}$, Soylu ve ark. (2011) $21,0-83,0 \mathrm{~kg} / \mathrm{da}$ arasında bulmuşlardır. Bu çalışmadan elde edilen tane verimlerine ait değerler önceki çalışma sonuçları ile önemli oranda benzerlik göstermekte olup farklılıkların çevre, genotip ve tarımsal uygulamalardan kaynaklandığı düşünülmektedir.
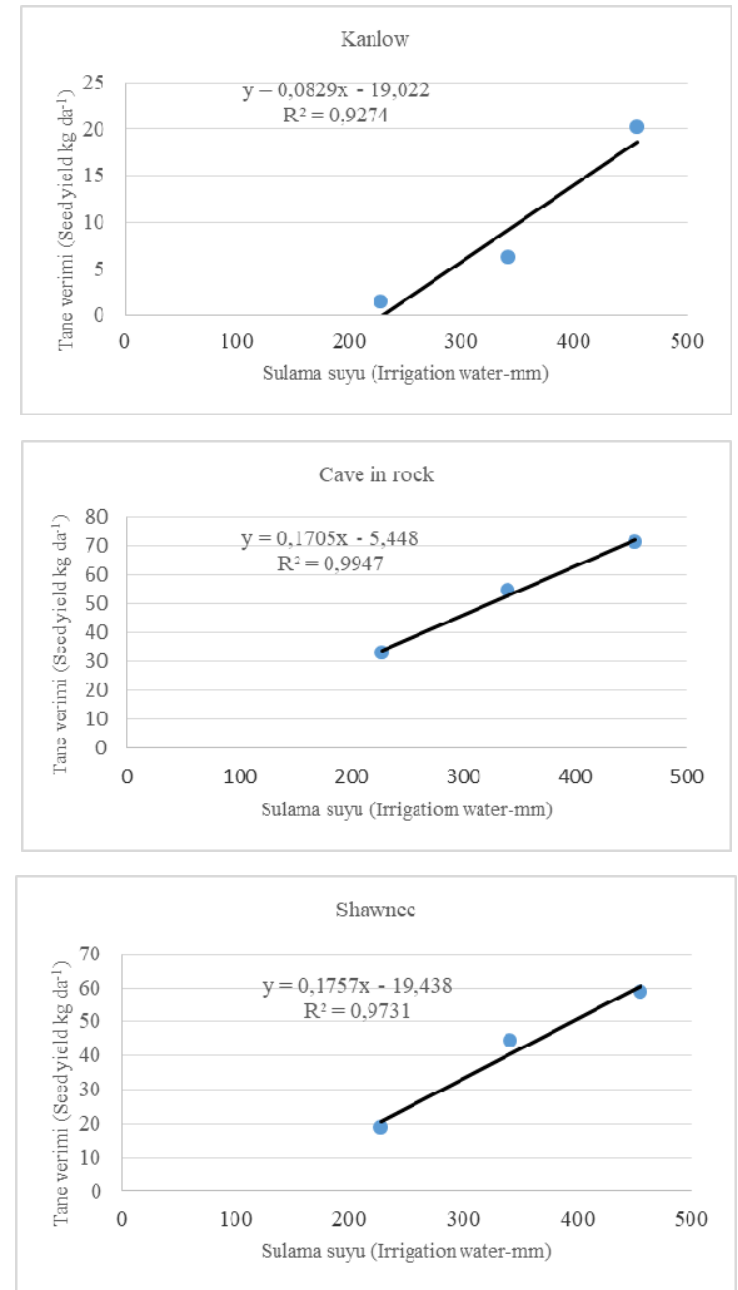

Şekil 1. Su kısıtlaması koşullarında dallı darı çeşitlerinin su ve tane verimi arasındaki ilișki.

Figure 1. Relationship between water and seed yield of switchgrass varieties in water deficit conditions. 


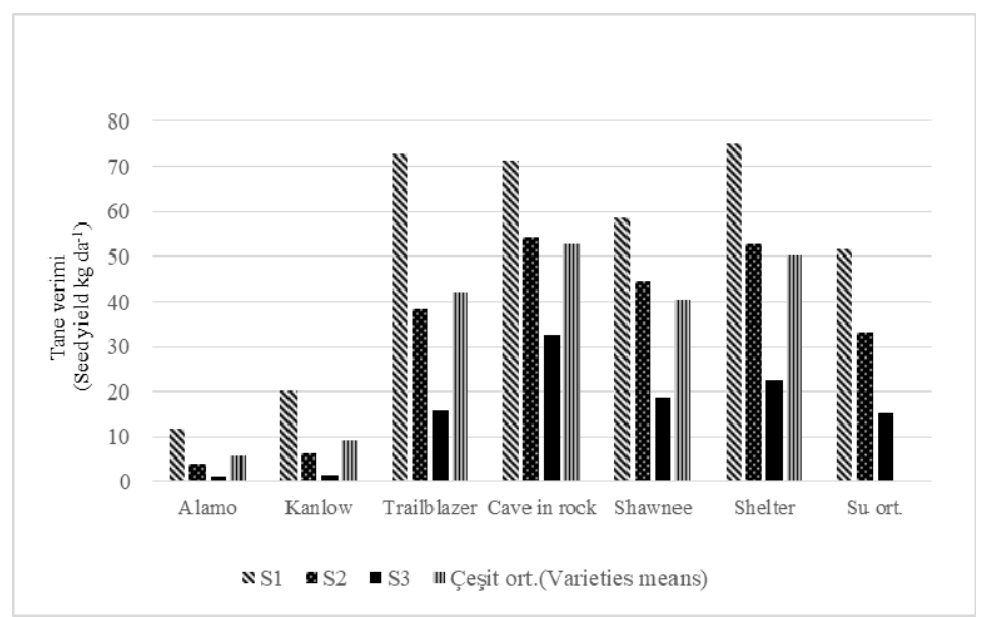

Şekil 2. Dallı darı çeşitlerinin farklı su kısıtlaması şartlarında (S1-S2-S3 ${ }^{\S}$ ) üç y1llık tane verimleri ortalaması (kg/da).

Figure 2. Average of three-year seed yields switchgrass varieties under different water deficit ( $\left.1-\mathrm{S} 2-\mathrm{S} 3^{\S}\right) \mathrm{conditions}\left(\mathrm{kg} \mathrm{da}^{-1}\right)$.

$\S_{\left[\mathrm{S}_{1}\right.}$ : Tam sulama, eksik nemin tarla kapasitesine getirilmesi; $\mathrm{S}_{2}: \mathrm{S}_{1}$ 'in $\% 75^{\prime}$ i kadar sulama; $\mathrm{S}_{3}: \mathrm{S}_{1}$ 'in \% 50 ' si kadar sulama

$\S\left(\mathrm{S}_{1}\right.$ : Full-irrigation with no water deficit, $\mathrm{S}_{2}: 75 \%$ of $\mathrm{S}_{1}$ irrigation, $\mathrm{S}_{3}: 50 \%$ of $\mathrm{S}_{1}$ irrigation)].

Çizelge 3. Su kısıtlaması koşulları altında dallı darı çeşitlerinin çiçeklenme tarihleri.

Table 3. Flowering dates of switchgrass varieties under water deficit conditions.

\begin{tabular}{|c|c|c|c|c|c|c|c|}
\hline $\begin{array}{l}\text { Yillar } \\
\text { Years }\end{array}$ & $\begin{array}{l}\text { Su kisitı/Çeşit } \\
\text { Water deficit/ } \\
\text { Varieties }\end{array}$ & Alamo & Kanlow & Trailblazer & Cave in rock & Shawnee & Shelter \\
\hline 2016 & $\begin{array}{l}\mathrm{S}_{1} \\
\mathrm{~S}_{2} \\
\mathrm{~S}_{3} \\
\end{array}$ & $\begin{array}{l}24 \mathrm{~A} \breve{g} . \\
30 \mathrm{Ag} . \\
4 \text { Ey. }\end{array}$ & 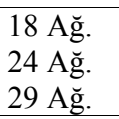 & $\begin{array}{l}24 \text { Tem. } \\
28 \text { Tem. } \\
4 \text { A } \breve{g} .\end{array}$ & $\begin{array}{l}21 \text { Tem. } \\
24 \text { Tem. } \\
28 \text { Tem. }\end{array}$ & $\begin{array}{l}23 \text { Tem. } \\
26 \text { Tem. } \\
2 \text { A } \breve{g} .\end{array}$ & $\begin{array}{l}21 \mathrm{Tem} . \\
24 \mathrm{Tem} . \\
1 \mathrm{Ağ.}\end{array}$ \\
\hline 2017 & $\begin{array}{l}\mathrm{S}_{1} \\
\mathrm{~S}_{2} \\
\mathrm{~S}_{3}\end{array}$ & $\begin{array}{l}26 \mathrm{Ağ.} \\
29 \mathrm{Ağ} . \\
3 \text { Ey. }\end{array}$ & $\begin{array}{l}20 \mathrm{A \breve {g }} . \\
24 \mathrm{Ağ} . \\
29 \mathrm{Ağ} .\end{array}$ & $\begin{array}{l}22 \text { Tem. } \\
25 \text { Tem. } \\
30 \text { Tem. }\end{array}$ & $\begin{array}{l}20 \text { Tem. } \\
22 \text { Tem. } \\
27 \text { Tem. }\end{array}$ & $\begin{array}{l}19 \text { Tem. } \\
24 \text { Tem. } \\
29 \text { Tem. }\end{array}$ & $\begin{array}{l}19 \text { Tem. } \\
24 \text { Tem. } \\
28 \text { Tem. }\end{array}$ \\
\hline 2018 & $\begin{array}{l}\mathrm{S}_{1} \\
\mathrm{~S}_{2} \\
\mathrm{~S}_{3}\end{array}$ & $\begin{array}{l}30 \text { Tem. } \\
14 \text { Ağ. } \\
30 \text { Ağ. }\end{array}$ & $\begin{array}{l}25 \mathrm{Tem} . \\
2 \mathrm{Ağ.} \\
18 \mathrm{Ağ.}\end{array}$ & $\begin{array}{l}6 \text { Tem. } \\
9 \text { Tem. } \\
18 \text { Tem. }\end{array}$ & $\begin{array}{l}3 \text { Tem. } \\
6 \text { Tem. } \\
11 \text { Tem. }\end{array}$ & $\begin{array}{l}3 \text { Tem. } \\
5 \text { Tem. } \\
12 \text { Tem. }\end{array}$ & $\begin{array}{l}2 \text { Tem. } \\
7 \text { Tem. } \\
13 \text { Tem. }\end{array}$ \\
\hline
\end{tabular}

$\mathrm{S}_{1}$ : Tam sulama, eksik nemin tarla kapasitesine getirilmesi; $\mathrm{S}_{2}$ : $\mathrm{S}_{1}$ ' in \% 75' i kadar sulama; $\mathrm{S}_{3}$ : $\mathrm{S}_{1}$ ' in \% 50' si kadar sulama.

( $\mathrm{S}_{1}$ : Full-irrigation with no water deficit, $\mathrm{S}_{2}: 75 \%$ of $\mathrm{S}_{1}$ irrigation, $\mathrm{S}_{3}: 50 \%$ of $\mathrm{S}_{1}$ irrigation).

Çizelge 4. Kısıntılı sulama koşulları altında dallı darı çeşitlerinin çeşitli özelliklerine ait varyans analizi.

Table 4. ANOVA for some agronomic traits of switchgrass varieties under water deficit conditions.

\begin{tabular}{|c|c|c|c|c|c|c|c|}
\hline \multirow{2}{*}{$\begin{array}{l}\text { Varyasyon kaynakları } \\
\text { Source of variation }\end{array}$} & \multirow[b]{2}{*}{$\mathrm{DF}$} & \multicolumn{6}{|c|}{ Kareler ortalamas1 (Mean square) } \\
\hline & & \multicolumn{2}{|c|}{$\begin{array}{l}\text { Tane verimi } \\
\text { Seed yield }\end{array}$} & \multicolumn{2}{|c|}{$\begin{array}{c}\text { Bin tane ağ. } \\
\text { Thousand-kernel weights }\end{array}$} & \multicolumn{2}{|c|}{$\begin{array}{l}\text { Hasat indeksi } \\
\text { Harvest index }\end{array}$} \\
\hline Y1l (A) Year & 2 & 5786,9 & $*$ & 0,120 & $*$ & 27,27 & $*$ \\
\hline Tek\#[Y11] Rep*(Year) & 6 & 25,3 & & 0,020 & & 0,15 & \\
\hline $\mathrm{Su}(\mathrm{B})$ Irrigation & 2 & 17699,6 & $*$ & 0,510 & $*$ & 25,48 & $*$ \\
\hline Y11*Su (AxB) Year* Irr. & 4 & 709,1 & $*$ & 0,005 & & 4,01 & $*$ \\
\hline Hata-1 Error-1 & 12 & 10,6 & & 0,010 & & 0,15 & \\
\hline Çeşit (C) Variety & 5 & 11496,8 & $*$ & 4,230 & $*$ & 50,31 & $*$ \\
\hline Y1l x Çeşit (AxC) Year*Variety & 10 & 541,0 & $*$ & 0,004 & & 4.58 & $*$ \\
\hline Su x Çeşit $(\mathrm{BxC})$ Irr. ${ }^{*}$ Varieties & 10 & 819,6 & $*$ & 0,3000 & $*$ & 1,75 & $*$ \\
\hline$(\mathrm{AxBxC})$ & 20 & 127,0 & $*$ & 0,005 & & 0,76 & $*$ \\
\hline Hata-2 (Error-2) & 90 & 7,3 & & 0,007 & & 0,12 & \\
\hline CV $(0,05)$ & & 8,1 & & 6,1 & & 18,1 & \\
\hline
\end{tabular}

*: indicates significance at 0,05 respectively. CV: Coefficient of variation. 
E. GÖNÜLAL, S. SOYLU: KISINTILI SULAMA KOSULLARINDA DALLI DARI (Panicum virgatum L.) ÇEŞITLERININ TANE VERIMI VE BAZI ÖZELLIKLERININ BELIRLENMESi

Çizelge 5. Kısıntılı sulama koşulları altında dallı darı çeşitlerinin üç yıllık tane verimine ait ortalama değerler (kg/da).

Table 5. Average values of three years seed yield of switchgrass varieties under water deficit conditions $\left(\mathrm{kg} \mathrm{da}^{-1}\right)$.

\begin{tabular}{|c|c|c|c|c|c|c|c|c|}
\hline $\begin{array}{l}\text { Y1llar } \\
\text { (Years) }\end{array}$ & $\begin{array}{l}\text { Su kısıntısı/Çeşitler } \\
\text { Water deficit/ } \\
\text { Varieties }\end{array}$ & Alamo & Kanlow & Trailblazer & Cave in rock & Shawnee & Shelter & Mean \\
\hline \multirow{4}{*}{2016} & $\mathrm{~S}_{1}$ & $8,3 \mathrm{~s}-\mathrm{u}$ & $12,3 \mathrm{rs}$ & $66 \mathrm{~d}-\mathrm{f}$ & $59,3 \mathrm{gh}$ & $44,9 \mathrm{k}$ & $66,4 \mathrm{~d}-\mathrm{f}$ & $42,9 \mathrm{c}$ \\
\hline & $\mathrm{S}_{2}$ & $4,3 u-x$ & $4,6 \mathrm{u}-\mathrm{w}$ & $20 \mathrm{p}$ & $20,5 \mathrm{op}$ & $28,1 \mathrm{n}$ & $36,3 \mathrm{~lm}$ & $19 \mathrm{f}$ \\
\hline & $\mathrm{S}_{3}$ & $0,2 \mathrm{x}$ & $0,3 \mathrm{w}-\mathrm{x}$ & $3 v-x$ & $3,7 \mathrm{v}-\mathrm{x}$ & $32 \mathrm{v}-\mathrm{x}$ & $5,1 \mathrm{t}-\mathrm{v}$ & $2,6 \mathrm{~g}$ \\
\hline & Mean & 4,31 & $5,7 \mathrm{kl}$ & $29,8 \mathrm{~h}$ & $27,8 \mathrm{~h} 1$ & $25,4_{1}$ & $35,9 \mathrm{~g}$ & $21,5 \mathrm{~b}$ \\
\hline \multirow{4}{*}{2017} & $\mathrm{~S}_{1}$ & 12,2 rs & $15 \mathrm{qr}$ & $62,3 \mathrm{fg}$ & $69,3 \mathrm{~cd}$ & $64,3 \mathrm{ef}$ & $73,7 \mathrm{bc}$ & $49,5 \mathrm{~b}$ \\
\hline & $\mathrm{S}_{2}$ & $4,7 \mathrm{uv}$ & $5 \mathrm{t}-\mathrm{v}$ & $47,9 \mathrm{jk}$ & $68,6 \mathrm{de}$ & $49,4 \mathrm{j}$ & $67,3 \mathrm{de}$ & $40,5 \mathrm{~d}$ \\
\hline & $\mathrm{S}_{3}$ & $2,2 \mathrm{v}-\mathrm{x}$ & $2 v-x$ & $26,9 \mathrm{n}$ & 58,3 g-1 & $33,4 \mathrm{~m}$ & 38,11 & $26,8 \mathrm{e}$ \\
\hline & Mean & $6,4 \mathrm{kl}$ & $7,3 \mathrm{k}$ & $45,7 \mathrm{f}$ & $65,4 \mathrm{a}$ & $49 \mathrm{de}$ & $59,7 \mathrm{~b}$ & $38,9 \mathrm{a}$ \\
\hline \multirow{4}{*}{2018} & $\mathrm{~S}_{1}$ & $15 \mathrm{qr}$ & $33,1 \mathrm{~m}$ & $89,3 \mathrm{a}$ & $85,3 \mathrm{a}$ & $66,5 \mathrm{~d}-\mathrm{f}$ & $85 \mathrm{a}$ & $62,4 \mathrm{a}$ \\
\hline & $\mathrm{S}_{2}$ & $3,4 v-x$ & $9,1 \mathrm{st}$ & $47 \mathrm{jk}$ & $73,9 \mathrm{~b}$ & $55,2 \mathrm{~h} 1$ & 54,31 & $40,5 \mathrm{~d}$ \\
\hline & $\mathrm{S}_{3}$ & $1,3 v-x$ & $2,1 \mathrm{v}-\mathrm{x}$ & $17,7 \mathrm{pq}$ & $35,7 \mathrm{~lm}$ & $19,4 \mathrm{p}$ & 24,7 no & $16,8 \mathrm{f}$ \\
\hline & Mean & $6,6 \mathrm{kl}$ & $14,8 \mathrm{j}$ & $51,3 \mathrm{~d}$ & $65 \mathrm{a}$ & 47,1 ef & $54,7 \mathrm{c}$ & $39,9 \mathrm{a}$ \\
\hline \multirow{4}{*}{$\begin{array}{c}2016-18 \\
\text { Ort.(mean) }\end{array}$} & $\mathrm{S}_{1}$ & $11,9 \mathrm{k}$ & 20,2 h1 & $72,7 \mathrm{ab}$ & $71,3 \mathrm{~b}$ & $58,6 \mathrm{c}$ & $75 \mathrm{a}$ & $51,6 \mathrm{a}$ \\
\hline & $\mathrm{S}_{2}$ & 4,11 & 6,21 & $38,3 \mathrm{f}$ & $54,3 \mathrm{~d}$ & $44,3 \mathrm{e}$ & $52 \mathrm{~d}$ & $33,3 \mathrm{~b}$ \\
\hline & $\mathrm{S}_{3}$ & $1,2 \mathrm{~m}$ & $1,4 \mathrm{~m}$ & $15,8 \mathrm{j}$ & $32,6 \mathrm{~g}$ & $18,7_{1}$ & $22,6 \mathrm{~h}$ & $15,4 \mathrm{c}$ \\
\hline & Mean & $5,7 \mathrm{f}$ & $9,3 \mathrm{e}$ & $42,3 \mathrm{c}$ & $52,7 \mathrm{a}$ & $40,5 \mathrm{~d}$ & $50,1 \mathrm{~b}$ & \\
\hline $\operatorname{LSD}(0,05)$ & A: 1,35 & B: 1,38 & C: 1,45 & AxB: 2,34 & $\mathrm{AxC}: 2,51$ & $\mathrm{BxC}: 2,5$ & $\mathrm{AxBxC}:$ & 35 \\
\hline
\end{tabular}

$\mathrm{S}_{1}$ : Tam sulama, eksik nemin tarla kapasitesine getirilmesi; $\mathrm{S}_{2}$ : $\mathrm{S}_{1}$ 'in \% 75' i kadar sulama; $\mathrm{S}_{3}$ : $\mathrm{S}_{1}$ 'in \% 50' si kadar sulama.

$\left(\mathrm{S}_{1}:\right.$ Full-irrigation with no water deficit, $\mathrm{S}_{2}: 75 \%$ of $\mathrm{S}_{1}$ irrigation, $\mathrm{S}_{3}: 50 \%$ of $\mathrm{S}_{1}$ irrigation).

$\mathrm{A}=$ Yı1 (Year), $\mathrm{B}=\mathrm{Su}$ kısıtlaması uygulamaları (Water deficit), $\mathrm{C}=$ Çeşit (Varieties).

\section{Bin tane ağırlı̆ğ}

Çalışmada tane verimine benzer şekilde ilk yıla göre ikinci ve üçüncü yılda bin tane ağırlı̆̆ artmış ve 2016 yılında $1,29 \mathrm{~g}$ olan bin tane ağırlı̆̆1, 2017 y1lında $1,36 \mathrm{~g}$ ve 2018 y1lında ise 1,34 g olmuştur. $\mathrm{Su}$ kısıtlaması çiçeklenme tarihini geciktirmiş (Çizelge 3) ve tane gelişimi için gerekli olan süre (generatif dönem) kısalarak, bin tane ağırlığını olumsuz şekilde etkilemiştir (Çizelge 6).

Çeşit ortalamaları üzerinden bakıldığında Soylu ve ark. (2011)'nın sonuçlarına benzer şekilde en düşük bin tane ağırlığı değerleri Alamo $(0,81 \mathrm{~g})$ ve Kanlow $(0,82 \mathrm{~g})$ çeşitlerinden elde edildiği, en yüksek değerler Cave in rock $(1,65 \mathrm{~g})$, Shawnee $(1,57 \mathrm{~g})$ ve Shelter $(1,57 \mathrm{~g})$ çeşitlerinden elde edilmiştir (Çizelge 6). İnteraksiyon açısından incelendiğinde Cave in rock, Shawnee ve Shelter çeşitlerinin tüm sulama uygulamalarında en yüksek değeri verdiği ve çeşitlerin bin tane değerlerinin $0,72 \mathrm{~g}\left(\mathrm{~S}_{3}\right.$ konusundaki Alamo çeşidi) ile $1,70 \mathrm{~g}$ $\left(\mathrm{S}_{1}\right.$ konusundaki Cave in rock çeşidi) arasında oluştuğu saptanmış olup bu değerler Boe (2007), Das ve ark. (2009), Soylu ve ark. (2011)'nın sonuçları ile benzerlik göstermektedir. Önceki çalışma sonuçları ile bu çalışmadan elde edilen değerler arasındaki farklılıkların çevre, genotip ve yetiştirme tekniklerinden kaynaklanması olasıdır.

\section{Hasat indeksi}

Çalışmada tane verimine benzer şekilde artan su kısıtlılığı ile birlikte hasat indeksi de azalmıştır. En yüksek değer tam su uygulamasından (\% 2,52), en düşük değer ise \% 50 su kısıtı konusundan (\% $1,17)$ elde edilmiştir. Yıllara göre en yüksek değer 2017 yılında (\% 2,67) elde edilirken, en düşük değer 2016 yılından $(\% \quad 1,26)$ elde edilmiştir (Çizelge 7).

Çeşitler ortalaması incelendiğinde biyokütle verimi ve hasat indeksi arasında negatif bir ilişki olduğu (Das ve ark., 2009), tane verimi düşük, buna karşılık biyokütle verimi yüksek olan lowland ekotipindeki Alamo $(\% 0,21)$ ve Kanlow $(\% 0,32)$ 
çeşitlerinden en düşük hasat indeksi değeri belirlenmiştir. En yüksek değer ise tane veriminin en fazla olduğu Cave in rock çeşidinde $(\% 3,57)$ saptanmıştır (Çizelge 5 ve 7). İnteraksiyon açısından bakıldığında çalışmada en yüksek ve düşük hasat indeksi değerleri $\mathrm{S}_{1}$ konusunda Cave in rock $(\% 4,20)$ ile Alamo $(\% 0,39)$ çeşitlerinden, $\mathrm{S}_{2}$ konusunda Cave in rock çeşidiyle $(\% 3,69)$ Alamo $(\% 0,18)$ çeşitlerinden, $\mathrm{S}_{3}$ konusunda ise Cave rock $(\% 2,81)$ ile Alamo ve Kanlow $(\% 0,06)$ çeşitlerinde ölçülmüştür. (Çizelge 7.) Tane veriminin toplam biyolojik verime oranı olarak da tanımlanan hasat endeksi değerinin yüksek olması, biyoyakıt üretiminde istenmeyen bir durum olup (Houghton ve ark., 2006), biyoyakıt elde edilmesi amaçlı dallı darı 1slahında, birim alanda tane veriminin bitkinin çoğaltılmasına yetecek kadar uygun oranda olması yeterlidir. Çalışmadaki biyoyakıt olarak kullanılan lowland ekotipindeki Kanlow ve Alamo çeşitlerine ait hasat endeksi değerleri söz konusu amaca uygun değerler vermiştir. Çalışma bulgularına benzer şekilde daha önceki çalışmada hasat endeksi değerini Boe (2007), \% 1,57-3,52 olarak bulmuş ve Das ve ark. (2009) ise, tane verimi ve biyokütle arasında negatif bir ilişki olduğu, tane verimi ve hasat indeksi arasında ise pozitif bir ilişki olduğunu bildirmişlerdir.

Çizelge.6. Su kısıtlaması koşulları altında dallı darı çeşitlerinin üç yıllık bin tane ağırlığına ait ortalama değerler (g).

Table 6. Average values of three years thousand-kernel weights of swicthgrass varieties under water deficit conditions (g).

\begin{tabular}{|c|c|c|c|c|c|c|c|c|}
\hline $\begin{array}{l}\text { Y1llar } \\
\text { Years }\end{array}$ & $\begin{array}{l}\text { Su kısıtt//Çeşitler } \\
\text { Water deficit/Varieties }\end{array}$ & Alamo & Kanlow & Trailblazer & Cave in rock & Shawnee & Shelter & Mean \\
\hline \multirow{4}{*}{2016} & $\mathrm{~S}_{1}$ & 0,85 & 0,83 & 1,68 & 1,63 & 1,57 & 1,58 & 1,36 \\
\hline & $\mathrm{S}_{2}$ & 0,79 & 0,81 & 1,49 & 1,58 & 1,52 & 1,57 & 1,29 \\
\hline & $\mathrm{S}_{3}$ & 0,71 & 0,68 & 1,17 & 1,52 & 1,41 & 1,46 & 1,16 \\
\hline & Mean & 0,9 & 0,77 & 1,45 & 1,58 & 1,5 & 1,53 & $1,27 \mathrm{~b}$ \\
\hline \multirow{4}{*}{2017} & $\mathrm{~S}_{1}$ & 0,94 & 0,89 & 1,68 & 1,75 & 1,67 & 1,73 & 1,44 \\
\hline & $\mathrm{S}_{2}$ & 0,81 & 0,87 & 1,57 & 1,68 & 1,62 & 1,57 & 1,35 \\
\hline & $\mathrm{S}_{3}$ & 0,73 & 0,72 & 1,4 & 1,69 & 1,6 & 1,49 & 1,27 \\
\hline & Mean & 0,82 & 0,83 & 1,55 & 1,71 & 1,63 & 1,6 & $1,36 \mathrm{a}$ \\
\hline \multirow{4}{*}{2018} & $\mathrm{~S}_{1}$ & 0,92 & 0,9 & 1,7 & 1,72 & 1,67 & 1,7 & 1,43 \\
\hline & $\mathrm{S}_{2}$ & 0,82 & 0,88 & 1,58 & 1,7 & 1,63 & 1,58 & 1,37 \\
\hline & $\mathrm{S}_{3}$ & 0,73 & 0,8 & 1,3 & 1,57 & 1,48 & 1,5 & 1,23 \\
\hline & Mean & 0,82 & 0,86 & 1,53 & 1,66 & 1,59 & 1,59 & $1,34 \mathrm{a}$ \\
\hline \multirow{4}{*}{$\begin{array}{l}2016-18 \\
(3 \text { y1l ort.) }\end{array}$} & $\mathrm{S}_{1}$ & 0,901 & $0,87 \mathrm{ij}$ & $1,69 \mathrm{a}$ & $1,70 \mathrm{a}$ & 1,63 a-d & $1,67 \mathrm{ab}$ & $1,41 \mathrm{a}$ \\
\hline & $\mathrm{S}_{2}$ & $0,81 \mathrm{jk}$ & $0,85 \mathrm{ij}$ & $1,55 \mathrm{e}-\mathrm{g}$ & $1,65 \mathrm{a}-\mathrm{c}$ & $1,59 \mathrm{c}-\mathrm{e}$ & $1,57 \mathrm{~d}-\mathrm{f}$ & $1,34 \mathrm{~b}$ \\
\hline & $\mathrm{S}_{3}$ & 0,721 & $0,73 \mathrm{kl}$ & $1,29 \mathrm{~h}$ & 1,59 b-e & $1,50 \mathrm{fg}$ & $1,48 \mathrm{~g}$ & $1,22 \mathrm{c}$ \\
\hline & Mean & $0,81 \mathrm{~d}$ & $0,82 \mathrm{~d}$ & $1,51 \mathrm{c}$ & $1,65 \mathrm{a}$ & $1,57 \mathrm{~b}$ & $1,57 \mathrm{~b}$ & 1,32 \\
\hline $\begin{array}{l}\operatorname{LSD}(0,05) \\
\mathrm{CV}: \% 6.1\end{array}$ & A: 0,048 & B: 0,049 & C: 0,047 & AxB: ns & $\mathrm{AxC}: \mathrm{ns}$ & $\mathrm{B} * \mathrm{C}: 0,08$ & AxBxC: ns & \\
\hline
\end{tabular}

$\mathrm{S}_{1}$ : Tam sulama, eksik nemin tarla kapasitesine getirilmesi; $\mathrm{S}_{2}$ : $\mathrm{S}_{1}$ 'in \% 75' i kadar sulama; $\mathrm{S}_{3}$ : $\mathrm{S}_{1}$ 'in \% 50' si kadar sulama. $\left(\mathrm{S}_{1}\right.$ : Full-irrigation with no water deficit, $\mathrm{S}_{2}: 75 \%$ of $\mathrm{S}_{1}$ irrigation, $\mathrm{S}_{3}: 50 \%$ of $\mathrm{S}_{1}$ irrigation).

$\mathrm{A}=\mathrm{Y} 11$ (Year), $\mathrm{B}=\mathrm{Su}$ kısıtlaması uygulamaları (Water deficit), $\mathrm{C}=$ Çeşit (Varieties). 
Çizelge 7. Su kısıtlaması koşulları altında dallı darı çeşitlerinin üç yıllık hasast indeksine ait ortalama değerler (\%).

Table 7. Average values of three years harvest index of switchgrass varieties under water deficit conditions (\%).

\begin{tabular}{|c|c|c|c|c|c|c|c|c|}
\hline $\begin{array}{l}\text { Yillar } \\
\text { Years }\end{array}$ & $\begin{array}{l}\text { Su kısıtı/Çeşitler } \\
\text { Water deficit/Varieties }\end{array}$ & Alamo & Kanlow & Trailblazer & Cave in rock & Shawnee & Shelter & $\begin{array}{l}\text { Ort. } \\
\text { Mean }\end{array}$ \\
\hline \multirow{4}{*}{2016} & $\mathrm{~S}_{1}$ & $0,32 \mathrm{pq}$ & $0,50 \mathrm{o}-\mathrm{q}$ & 3,21 ef & $3,98 \mathrm{~cd}$ & $2,65 \mathrm{gh}$ & $3,75 \mathrm{de}$ & $2,40 \mathrm{~b}$ \\
\hline & $\mathrm{S}_{2}$ & $0,20 \mathrm{q}$ & $0,25 \mathrm{q}$ & $1,101-n$ & $1,41 \mathrm{kl}$ & $2,01 \mathrm{ij}$ & $2,22 \mathrm{~h}-\mathrm{j}$ & $1,20 \mathrm{~d}$ \\
\hline & $\mathrm{S}_{3}$ & $0,01 \mathrm{q}$ & $0,02 \mathrm{q}$ & $0,19 \mathrm{q}$ & $0,30 \mathrm{pq}$ & $0,25 \mathrm{q}$ & $0,35 \mathrm{pq}$ & 0,19 e \\
\hline & Mean & $0,18 \mathrm{j}$ & $0,25 \mathrm{j}$ & $1,50_{1}$ & $1,90 \mathrm{gh}$ & $1,63 \mathrm{~h}_{1}$ & $2,11 \mathrm{fg}$ & $1,26 \mathrm{c}$ \\
\hline \multirow{4}{*}{2017} & $\mathrm{~S}_{1}$ & 0,46 o-q & $0,55 \mathrm{n}-\mathrm{q}$ & $2,81 \mathrm{fg}$ & $4,96 \mathrm{~b}$ & $3,77 \mathrm{~d}$ & $3,96 \mathrm{~cd}$ & $2,75 \mathrm{a}$ \\
\hline & $\mathrm{S}_{2}$ & $0,20 \mathrm{q}$ & $0,21 \mathrm{q}$ & $2,83 \mathrm{fg}$ & $5,83 \mathrm{a}$ & $4,01 \mathrm{~cd}$ & $4,36 \mathrm{c}$ & $2,90 \mathrm{a}$ \\
\hline & $\mathrm{S}_{3}$ & $0,11 \mathrm{q}$ & $0,09 \mathrm{q}$ & $1,67 \mathrm{jk}$ & $5,89 \mathrm{a}$ & $3,45 \mathrm{de}$ & $2,83 \mathrm{fg}$ & $2,34 \mathrm{~b}$ \\
\hline & Mean & $0,25 \mathrm{j}$ & $0,28 \mathrm{j}$ & $2,44 \mathrm{de}$ & $5,56 \mathrm{a}$ & $3,75 \mathrm{~b}$ & $3,72 \mathrm{~b}$ & $2,67 \mathrm{a}$ \\
\hline \multirow{4}{*}{2018} & $\mathrm{~S}_{1}$ & $0,41 \mathrm{o}-\mathrm{q}$ & $0,84 \mathrm{~m}-\mathrm{p}$ & $3,52 \mathrm{de}$ & $3,65 \mathrm{de}$ & $2,65 \mathrm{gh}$ & $3,48 \mathrm{de}$ & $2,42 \mathrm{~b}$ \\
\hline & $\mathrm{S}_{2}$ & $0,13 \mathrm{q}$ & $0,31 \mathrm{pq}$ & $2,0 \mathrm{ij}$ & $3,84 \mathrm{~cd}$ & $2,82 \mathrm{fg}$ & $2,68 \mathrm{f}-\mathrm{h}$ & $1,97 \mathrm{c}$ \\
\hline & $\mathrm{S}_{3}$ & $0,06 \mathrm{q}$ & $0,08 \mathrm{q}$ & $0,921-0$ & $2,25 \mathrm{~h}_{1}$ & $1,22 \mathrm{k}-\mathrm{m}$ & $1,29 \mathrm{k}-\mathrm{m}$ & $0,97 \mathrm{~d}$ \\
\hline & Mean & $0,20 \mathrm{j}$ & $0,41 \mathrm{j}$ & $2,15 \mathrm{e}-\mathrm{g}$ & $3,25 \mathrm{c}$ & $2,23 \mathrm{~d}-\mathrm{f}$ & $2,48 \mathrm{~d}$ & $1,79 \mathrm{~b}$ \\
\hline \multirow{4}{*}{$\begin{array}{l}\text { 2016-18 } \\
\text { Ort.(Mean) }\end{array}$} & $\mathrm{S}_{1}$ & 0,39 h1 & $0,63 \mathrm{gh}$ & $3,18 \mathrm{c}$ & $4,20 \mathrm{a}$ & $3,01 \mathrm{~cd}$ & $3,73 \mathrm{~b}$ & $2,52 \mathrm{a}$ \\
\hline & $\mathrm{S}_{2}$ & $0,18 \mathrm{ij}$ & $0,26 \mathrm{ij}$ & $1,98 \mathrm{e}$ & $3,69 \mathrm{~b}$ & $2,95 \mathrm{~cd}$ & $3,08 \mathrm{~cd}$ & $2,02 \mathrm{~b}$ \\
\hline & $\mathrm{S}_{3}$ & $0,06 \mathrm{j}$ & $0,06 \mathrm{j}$ & $0,93 \mathrm{~g}$ & $2,81 \mathrm{~d}$ & $1,64 \mathrm{f}$ & $1,49 \mathrm{f}$ & $1,17 \mathrm{c}$ \\
\hline & Mean & $0,21 \mathrm{e}$ & $0,32 \mathrm{e}$ & $2,03 \mathrm{~d}$ & $3,57 \mathrm{a}$ & $2,53 \mathrm{c}$ & $2,77 \mathrm{~b}$ & 1,91 \\
\hline $\operatorname{LSD}(0,05)$ & $\mathrm{A}: 0,16$ & B: 0,16 & C: 0,19 & AxB: 0,28 & AxC: 0,32 & BxC: 0,32 & AxBxC:0,55 & \\
\hline
\end{tabular}

$\mathrm{S}_{1}$ : Tam sulama, eksik nemin tarla kapasitesine getirilmesi; $\mathrm{S}_{2}$ : $\mathrm{S}_{1}$ 'in \% 75' i kadar sulama; $\mathrm{S}_{3}$ : $\mathrm{S}_{1}$ 'in \% 50' si kadar sulama.

$\left(\mathrm{S}_{1}\right.$ : Full-irrigation with no water deficit, $\mathrm{S}_{2}: 75 \%$ of $\mathrm{S}_{1}$ irrigation, $\mathrm{S}_{3}: 50 \%$ of $\mathrm{S}_{1}$ irrigation).

$\mathrm{A}=$ Yı1 (Year), $\mathrm{B}=\mathrm{Su}$ kısıtlaması uygulamaları (Water deficit), $\mathrm{C}=$ Çeşit (Varieties).

\section{SONUÇ}

Marjinal ve su kısıtlılığı koşullarında, benzer bitkilere göre çok daha iyi performans gösteren Amerika'da yaygın olarak yetiştirilen ve 2000' li y1llardan sonra Avrupa ve Türkiye' de adaptasyon ve diğer çalışmaları yürütülen dallı darı bitkisi özellikle kuru alanlar ve su kısitlılığı olan alanlarda biyoyakıt, hayvan yemi, erozyonla mücadele ve çayır mera amenajmanında kullanılacak alternatif bir bitki olarak ön plana çıkmaktadır. Bu bitkinin yaygınlaşmasında en önemli konulardan biri de gerekli tohumluğun üretilebilmesidir. Türkiye'de bu bitki ile ilgili ilk çalışmalarının yapıldığı Konya
Bölgesinde üç y1l süreyle yürütülen bu çalışma ile bölgeye adapte olmuş lowland (ova) ve upland (yayla) ekotipindeki altı çeşidin sulu ve su kısıtllılığ koşullarındaki tane verimi ve diğer özellikleri incelenmiștir. Calıșmada özellikle hayvan beslemede kullanılan upland ekotipindeki çeșitlerin hem sulu, hem de su kısıtlılığı ortamlarında birim alandaki tane verimlerinin yüksek olduğu, çiçeklenme tarihlerinin ve çiçeklenmeden sonra kalan sürenin tanenin olgunlaşması için yeterli olduğu ve bu bitkinin tohumluklarının Orta Anadolu Bölgesi’nde ekonomik olarak üretilebileceği ortaya koyulmuştur.

\section{LITTERATÜR LİSTESI}

Anonymous. 2007. JMP ${ }^{\circledR}$ 11.2, Copyright C 2007 , SAS Institute Inc., Cary, NC, USA.

Anonim. 2017. Konya Toprak Su ve Çölleşme ile Mücadele Araştırma Enstitüsü Toprak Analiz Labaratuvarı.

Anonim. 2018. Konya Toprak Su ve Çölleşme ile Mücadele Araştırma Enstitüsü meteoroloji istasyonu verileri.
Boe, A. 2007. Variation between two switchgrass cultivars for components of vegetative and seed biomass. Crop Science 47 (2): 636-642. Doi: 10.2135/cropsci2006. 04.0260

Casler, M. D. 2012. Switchgrass Breeding, Genetics, and Genomics. Chapter 2, pp. 29-53. In: A. Monti (Ed.) A Valuable Biomass Crop for Energy. Doi: 10.1007/978-1-4471-2903-5. Springer-Verlag, London. 
Das, M. K., and C. M. Taliaferro. 2009. Genetic variability and interrelationships of seed yield and yield components in switchgrass. Euphytica 167: 95-105. Doi: 10.1007/s10681-008-9866-3.

David, K. and A. J. Ragauskas. 2010. Switchgrass as an energy crop for biofuel production: A review of its ligno-cellulosic chemical properties. Energy and Environmental Science 3 (9): 1182-1190. Doi:10.1039/B926617H.

Houghton, D., S. Weatherwax, and J. Ferrell. 2006. Breaking the bio-logical barriers to cellulosic ethanol: a joint research agenda. A research roadmap resulting from the biomass to biofuels workshop sponsored by US Dept of Energy. December 7-9, 2005, Rockville, p 57.

Hultquist, S. J., K. P. Vogel, D. J. Lee, K. Arumuganathan, and S. Kaeppler. 1996. Chloroplast DNA and Nuclear DNA content variations among cultivars of switchgrass, Panicum virgatum L. Crop Science 36 (4): 1049-1052. Doi:10.2135/cropsci1996.0011183X 003600040039x.

Kara, M. 2011. Sulama ve Sulama Tesisleri. Selçuk Üniv. Basımevi s.45-65, Konya.

Narasimhamoorthy, B., M. Saha, T. Swaller, and J. Bouton. 2008. Genetic diversity in switchgrass collections assessed by EST-SSR markers. BioEnergy Res. 1: 136146. Doi: 10.1007/s12155-008-9011-0.

Sar1, N. ve A. Ünay. 2015. Yulafta (Avena sativa L.) tane verimini etkileyen özelliklerin belirlenmesi. Tarla Bitkileri Merkez Araştırma Enstitüsü Dergisi 24 (2): 115-123. Doi:10.21566/tbmaed.76925.
Sharma, N., I. Piscioneri, and V. Pignatelli. 2003. An evaluation of biomass yield stability of switchgrass (Panicum virgatum L.) cultivars. Energy Conversion and Management 44 (18); 2953-2958. Doi: 10.1016/S0196-8904(03)00049-9.

Soylu, S., B. Sade, H. Öğüt, F. Akınerdem, M. Babaoğlu, R. Ada, T. Eryılmaz, Ö. Öztürk, and H. Oğuz. 2010. Investigation of agronomic potential of switchgrass (Panicum virgatum L.) as an alternative biofuel and biomass crop for Turkey, $18^{\text {th }}$ European Biomass Conforence Lyon, Fransa.

Soylu, S., B. Sade ve A. Şeflek. 2011. Dallı darının tohum üretim kapasitesinin araştırılması. Türkiye IV. Tohumculuk Kongresi Kitab1 Cilt 2: 138-143, 14-17 Haziran, Samsun.

Steel, R. G. D., and J. H. Torrie. 1980. Principles and Procedures of Statistics. Second Ed. McGraw-Hill Book Company Inc., New York.

Turan, İ. 2008. Kahramanmaraş Koşullarında Bazı Buğday, Arpa Ve Tritikale Çeşitlerinin Verim Ve Verim Özelliklerinin Belirlenmesi. Yüksek Lisans Tezi, Sütçü İmam Üniversitesi Fen Bilimleri Enstitüsü Tarla Bitkileri ABD, Kahramanmaraş.

Vogel, K. P. 2000. Improving warm-season forage grasses using selection, breeding, and biotechnology. pp 83106. In: Moore K. J, and B. E. Anderson (Eds.) Native warm-season grasses: research trends and issues. Vol 30. CSSA Spec. Publ., Madison, WI. 